\title{
DE GROOTE ÓLÁFS SAGA TRYGGVASONAR EN DE HALLFREDAR SAGA.
}

De onbekende compilator uit de 14 e eeuw heeft zijn Óláfs saga Tryggvasonar als een legkaart uit velerlei brokjes in elkaar gezet. Niemand betwijfelt dit, en over de herkomst van zijn materiaal heerscht eenstemmigheid ${ }^{1}$ ). Een bescheiden bijdrage tot de kennis van 's compilators werkwijze heb ik geleverd in mijn verhandeling over de Hallfreðar saga 2), waar ik getracht heb duidelijk te maken, op welke wijze in cap. 165 en 170 van de redactie $X$ en cap. 266 en 272 van de redactie $R^{3}$ ) de man zijn beide bronnen, Snorri's Óláfs saga en de Hallfreðar saga heeft dooreen gewerkt. Over omvangrijke stukken, bijv. cap. 175-241 in X, en $230-370$ in $R$, zijn de bronnen dadelijk aan te wijzen: deels zijn ze afzonderlijk bewaard, zooals de Laxdœla saga, de Eiríks saga rauða, de Hallfreðar saga; deels worden zij geciteerd, zooals de Færeyjinga saga, die als afzonderlijke saga verloren ging; en de kern wordt gevormd door de Óláfs saga's van Snorri en Gunnlaugr. Zelf voegde de compilator blijkbaar weinig toe. Ook dit betwijfelt niemand, dat red. $\mathrm{R}$ méér bronnen gebruikt heeft dan red. $X$, bijv. in de Eiríks saga rauða, waar hs. 1005 naast deze saga nog iets anders raadpleegde; maar over dit punt elders.

Aangaande cap. 224 en 332 (X en R) heerscht onzekerheid, waar de compilator hier zijn stof nam; of liever: voor zooverre mij bekend is, heeft nog geen philoloog in dezen een meening geuit.

Deze capita luiden in beide redacties aldus:

$\mathrm{X}$

$\mathbf{R}$

1. Pyri dróttning haföi fœtt sveinbarn, er pau Óláfr konungr

áttu; sá sveinn var bæ̃õi

mikill ok efniligr ok var

kallaðr Haraldr eptir móður-

om. 1005.

fọour sínum, unnu pau peim

sveini mikit ok hugŏu gott

til, at hann mundi foðaz upp

ok taka arf ok riki eptir foður

om. 1005.

sinn en hann lifŏi eigi fullt

ár frá pvi, er hann var foeddr;

pótti peim báoum pat mikill

skaði.

1) Björn Ólsen, Kronologiske Bemarkninger om Olaf Tryggvasons Regeringshistorie (Aarbøger 1878) id. Om Ari fródi (Aarbøger 1893). G. Storm, Snorre Sturlassöns Historieskrivning (1873)

K. Maurer, Über die Ausdrücke etc. (Beiersche Akademie 1867); id. Über Ari fróoi und seine Schriften (Germania 1891). Finnur Jónsson, Historie II (1901), blz. 772 vlgg. Mogk, Qeschichte (1901), blz. 804 vlgg.

2) De overlevering van de Hallfredar saga (Nederlandsche Akademie 1919).

3) De benaming $X$ paste ik in deze verhandeling toe op hs. 61 en verwanten (Fornmannasögur I-III); de benaming R op hs. 1005 (Flateyjarbók I). 
2. Pann vetr var mart íslend-

skra manna meő konungi,

pá var ok með hirōinni

Ingibjorg Tryggvadóttir, systir

óláfs konungs; hun

var vel til allra Ís-

islendskra manna 1005.

lendinga peira er par

váru en Kjartan var

henni kunnastr; pótti

honum ok skemtiligt

opt at tala við hana

pviat hun var bæői

vitr ok snjoll i máli.

3. Hallfreðr hafŏi komit

um sumarit austan

af Gautlandi; hann

hafơi verit með Rogn-

valdi Úlfssyni, er

pá var kominn til ríkis

í Vestra-Gautlandi.

Úlfr, faðir Rognvalds

var bróðir Sigrí̋ar

hinnar stórráóu ; váru

peir systkina synir

Óláfr konungr scenski ok

Rognvaldr; sagði Hallfreôr óláfi mart af Rognvaldi; sagði at hann var hraustr họfơingi ok stjórnsamr, orr af penningum, drenglyndr ok vinhollr. Sagð̋i Hallfreơr pat ok með, at Rognvaldr vildi hallaz til vináttu undir Óláf ok hafỡi pat talat fyrir honum, at hann mundi biðja Ingibjargar.

Á peim vetri kómu austan af Gautlandi sendimenn Rognvalds, fundu peir óláf ok báru peir fram erendi Rognvalds oll slík sem Hallfreðr hafð̈i oröi á komit, at hann vildi vera fullkominn vin

við 1005. 


\author{
$\mathrm{X}$ \\ Óláfs konungs, ok \\ par meŏ mælti Rognvaldr \\ til mægðar við \\ konung ok vildi fá \\ Ingibjargar.
}

Wat nu de eerste twee deelen (1 en 2) van dit hoofdstuk aangaat, dáár zijn de bronnen zonder bezwaar te herkennen. Op de eerste plaats heeft de compilator blijkbaar Gunnlaugr-Oddr ${ }^{1}$ ) gebruikt; op de tweede plaats de Laxdoela saga 2), maar op de derde plaats is onzekerheid. De uitgevers van het eenige hs. der Hallfreðar saga (132 Havn. A. M.), Th. Möbius en Guð̋randur Vigfússon ${ }^{3}$ ), hebben gemeend, dat dit stuk in Snorri's Óláfs saga stond (Heimskringla), maar reeds Storm heeft in zijn genoemd werk 4) de onjuistheid van deze meening aangetoond. Het stuk heeft een drieledigen inhoud.

Er wordt verteld:

a) dat Hallfreorr op bezoek is geweest bij Rognvaldr Ulfsson in Gautland;

b) dat Hallfreorr met lof over Rognvaldr spreekt tegenover den koning en een huwelijksaanzoek aankondigt;

c) dat een gezantschap van Rognvaldr 't huwelijksaanzoek komt overbrengen.

Er zijn nu drie mogelijkheden: ò alle drie de berichten zijn aan een Óláfs saga ontleend; òf ze zijn aan een Hallfreðar saga ontnomen; òf de drie berichten stammen uit verschillende bronnen, en dan is de combinatie door den compilator tot stand gebracht.

Laat ons de eerste mogelijkheid onderzoeken: de drie berichten stammen uit een óláfs saga. Dit is onwaarschijnlijk. In een saga van Óláfr Tryggvason is voor Hallfreôr nauwelijks plaats. In den ontzaglijken strijd tusschen het oude en het nieuwe, tusschen koningschap en aristocratie, Christendom en heidendom, die de IJslandsche traditie ons heeft overgeleverd; die de IJslandsche aristocratie, de bewaarders dier traditie, zoo buitengewoon boeide, omdat van den afloop van dien strijd ook het lot van haar schepping, de IJslandsche vrijheid, afhing, kon men tegenover óláfr sterkere persoonlijkheden plaatsen dan Hallfreorr ${ }^{5}$ ), die wel aantrekkelijk is als mensch, vooral voor ons, die een even belangrijken overgangstijd beleven, als hij deed; die ook groot is als kunstenaar, maar die altijd wankelt tusschen twee wereldbeschouwingen: de oude, die hem telkens wegtrekt, hem dwingt zich in de vaderlandsche veeten te mengen en zijn wraaklust uit te vieren, hem niðvísur laat maken op het Christendom; de nieuwe, die hem wel aantrekkelijk voorkomt, maar niet, omdat ze past bij zijn wezen, en voldoet aan een innerlijke behoefte, maar omdat ze hem

1) Aangenomen, dat Gunnlaugr Oddr's Oláfs saga twéémaal bewerkt heeft, zooals Björn Ólsen (Aarb. 1893) wil. Cap. 57 in den Havn. (1835); cap. 48 in den Holm. (1853).

2) Cap $41-43$ in de L. S. (1896).

3) Fornsögur (1860) blz. XI.

4) blz. 56 vigg.

5) Men vergelijke de uitnemende karakteristiek van Hallfreðr bij Maurer, die Bekehrung des Norwegsichen Stammes, I (1855) blz. 371 vlgg. 
wordt opgedrongen door den koning, wien te behagen voor hem alles is. Aan den grooten strijd, dien óláfr te strijden had, heeft Hallfreơr geen deel gehad, hij heeft te veel te vechten met zich zelf, om den koning te kunnen helpen; zijn lot interesseerde óláfr, maar hij heeft zeker nooit in gewichtige oogenblikken zijn raad ingeroepen, nooit hem voor belangrijke zendingen gebruikt. Het eenige, wat in een óláfs saga over Hallfreôr vermeld moet worden, is de eerste ontmoeting tusschen hen beiden en Hallfreðr's bij zijn zwakheid zoo passende koppigheid. Gunnlaugr-Oddr spreken over deze eerste ontmoeting 1), Snorri ${ }^{2}$ ) evenzoo, breeder en uitvoeriger, en alle drie putten ze uit de traditie, maar dan is ook voldoende over Hallfreðr in verband met Óláfr gepraat. Zijn verder lot kan in een Hallfreðar saga verteld worden; over Óláfr zijn grootschere dingen te melden. Hallfreơr verdwijnt in 't ontzaglijk gebeuren, ja, zijn verhouding tot den koning blijkt zoo slap te zijn, dat hij op 't moeilijkste oogenblik in 's konings leven de bevrediging van zijn wraaklust hooger stelt dan het zijn bij óláfr: als diens ondergang nabij is, trekt hij naar IJsland en laat Óláfr den doodsstrijd bij Svoldr alleen uitvechten.

Laat ons de tweede mogelijkheid onderzoeken: de drie berichten stammen uit een Hallfreðar saga. Dit is onmogelijk. Men neme in aanmerking, dat cap. $224(\mathrm{X}), 332(\mathrm{R})$ niet te scheiden is van cap. 241 (X), $370(\mathrm{R})$; in het eerste cap. wordt van het gezantschap verteld, dat het aanzoek komt overbrengen; in het tweede cap. wordt het antwoord meegedeeld en het huwelijk tusschen Ingibjorg en Rognvaldr vermeld. Zulk een uitvoerig bericht over het huwelijk van koning Óláfr's zuster past niet in een levensbeschrijving van Hallfreơr. De berichten moeten dus uit verschillende bronnen stammen. En dan is slechts éen oplossing mogelijk: het eerste bericht $(a)$ stamt uit een Hallfreðar saga; het derde $(c)$ uit een óláfs saga, en het tweede $(b)$ is uit de pen van den compilator zelven gevloeid, evenals de combinatie van $a$ met $c$ van hem is.

Als dit zoo is, bekruipt ons de vraag: welke Óláfs saga heeft hier den compilator aan zijn bericht geholpen? Wat vertellen de verschillende óláfs saga's over de zusters van Óláfr en haar mannen? Theodricus ${ }^{3}$ ) vertelt van drie zwagers, die met sorores getrouwd zijn: Erlingr, Porgeirr, Hyrningr. De Historia Norvegiae zwijgt, evenals Ágrip af Noregs konunga sogum; Gunnlaugr-Oddr ${ }^{4}$ ) kennen drie zwagers, die met systr getrouwd zijn: òok Erlingr, Porgeirr, Hyrningr, en bovendien de namen der zusters Ástríorr, Ingigerorr, Ingirior; uit het verband is op te maken, dat Gunnlaugr-Oddr de meisjes houden voor dochters van Loðinn en Ástrírr, dus voor stiefzusters van den koning. Snorri kent vier zwagers: twée, Erlingr en Rognvaldr, die met 's konings eigen zusters, Ástríor en Ingibjọrg, getrouwd zijn; en twéé, porgeirr en Hyrningr, die met stiefzusters Ingigerơr en Ingiriór getrouwd zijn ${ }^{6}$ ). Zijn opvatting van de familieverhoudingen is voortgevloeid uit zijn bekenden voorkeur voor de skaldenpoëzie boven zijn prozaïsche

1) Cap. 36 in den Havn. (1835); cap. 30 in den Holm. (1853).

2) Cap. 83 in de Heimskringla (1911).

3) G. Storm, Monumenta historica Norvegiae (1880) blz. 21.

4) Cap. 21-22 in den Holmianus (1853); de Havn. heeft hier een lacune.

5) Cap. 52 in de Heimskringla (1911). 
bronnen: waar hij bij Sighvatr Pórðarson 1), dien hij in zijn afzonderlijke saga van Óláfr Haraldsson ${ }^{2}$ ) en in die in de Heimskringla ${ }^{3}$ ) citeert en dus kent, vond, dat Erlingr en Rqgnvaldr met eigen zusters getrouwd zijn, gelooft hij dezen en wijkt van de voorstelling, die hij bij Gunnlaugr-Oddr vond, af. Merkwaardig is, dat Snorri van het huwelijk van Rognvaldr en Ingibjorg weet, maar 't niet vermeldt in zijn óláfs saga Tryggvasonar in de Heimskringla. Daarentegen vermeldt hij het wel in zijn afzonderlijke saga over Óláfr Haraldsson ${ }^{4}$ ). Deze houding van Snorri is, wanneer men met Sigurour Nordal 5 ) aanneemt, dat Snorri de afzonderlijke óláfs saga schreef vóór de Heimskringla, aldus te verklaren. In de eerste, de afzonderlijke saga, was een korte introductie van Rognvaldr noodzakelijk, een vermelding van het plaatsgegrepen huwelijk met Ingibjorg. Toen Snorri de Heimskringla bewerkte, wilde hij, aan de Óláfs saga Tryggvasonar werkende, de vermelding van het huwelijk blijkbaar uitstellen, tot hij op de gewenschte plaats in de óláfs saga gekomen was, maar toèn hij dit punt was genaderd, ontschoot hem de vermelding, en zóó treedt in de Heimskringla Rognvaldr volkomen onaangekondigd op, geheel tegen het gebruik der saga's in. Om tot ons uitgangspunt terug te keeren, onze compilator kan onmogelijk zijn bericht uit Snorri of Gunnlaugr-Oddr hebben. De eenige mogelijkheid is, dat hij 't bericht ontleend heeft, niet aan de eerste bewerking van Oddr door Gunnlaugr, maar aan de tweede, die verloren ging en hem doorloopend ten dienste moet hebben gestaan, juist in die stukken, die de kersteningsgeschiedenis van het Noorden raakten ${ }^{6}$ ), die Gunnlaugr zelf weer uit vele vertellingen heeft verzameld, zooals zoo duidelijk blijkt uit zijn opmerking in cap. 176 (red. X), 307 (red. R). Is dit zoo, en niets spreekt tegen deze meening, dan hebben blijkbaar Snorri in zijn afzonderlijke óláfs saga en onze compilator dezelfde bron gehad, nl. Gunnlaugr, wat waarschijnlijk gemaakt wordt door de overeenstemming in hun beider bewoordingen:

Snorri

(cap. 30)

hann (= R.) réo fyrir V. Gautlandi. Úlfr, faðir R., var bróðir Sigriððar hinnar stórráóu, móour Óláfs Sviakonungs.

\section{Compilator $\mathrm{X} \quad \mathrm{R}$}

(cap. 224) (cap. 332)

hann $(=\mathrm{R}$.) var kominn til ríkis i V. Gautlandi. Úlfr, faǒir R., var bróőir Sigríðar hinnar stórráou ; váru peir systkina synir, Óláfr konungr sœnski ok $\mathrm{R}$.

Snorri kende het uitvoerige bericht in Gunnlaugr's tweede, verloren bewerking over het aanzoek van Rognvaldr en 't volgende huwelijk, maar

1) Erlingsflokkr Skjaldedigtning 1912 (I AB blz. 244 en 228).

2) Munch 1853 (Forelæsningskatalog). Een nieuwe uitgave van de afzonderlijke Óláfs saga Haraldssonar wordt voorbereid door prof. O. A. Johnsen in Christiania.

3) Cap. 22 en 67 (1911).

4) Cap. 30.

5) Om Olaf den helliges saga (1914 Kopenh, dissertatie).

B) Ik vestig hier de aandacht op de wenschelijkheid van een uitgave van de óláfs saga Tryggvasonar van Bergr Sokkason. 
zag - terecht - de noodzakelijkheid niet in van de overneming van het bericht in zijn geheel: hij had, in zijn afzonderlijke Óláfs saga, genoeg aan de korte introductie-opmerking over Rognvaldr; de compilator, 't uitvoerige boven alles prefereerend, neemt 't geheele bericht mee, dat bovendien in zänn Oláfs saga T. beter past dan in een óláfs saga H. Dat Snorri, behalve Gunnlaugr-Oddr, ook Gunnlaugr's tweede bewerking gekend heeft, is uit zijn óláfs saga Tryggvasonar, in de Heimskringla, te merken, vóóral in die deelen, die vertellen van de missie van Pangbrandr naar IJsland, van de houding van den koning tegenover de anwezige IJslanders in Niðaróss nà Pangbrandr's terugkomst, en van de aanneming van het Christendom op het alpingi, deelen, die immers mèt de vertellingen van Porvaldr en Stefnir zeker tot Gunnlaugr's tweede bewerking behoord hebben.

Het tweede bericht komt dan uit 's compilators eigen hoofd. Hij was wel gedwongen hier en daar wat bindingsstof te gebruiken om zijn materiaal aan elkaar te doen passen, maar hij is niet altijd gelukkig geweest, noch in het samenvoegen van zijn bouwstoffen, noch in het aanwenden van zijn bindingsstof. Zoo is bijv. in ons cap. 224 en 332 ( $X$ en $R$ ) de combinatie van Laxdœla saga met Oláfs saga bedenkelijk: nauwlijks heeft de compilator verteld van de meer dan vriendschappelijke verhouding tusschen Kjartan en Ingibjọrg, of hij begint met te verhalen van 't huwelijksaanzoek van Rognvaldr, dat door Ingibjorg in gunstigen zin beantwoord wordt. Even bedenkelijk is het verbinden van Hallfreorr's verblijf bij Rognvaldr en zijn terugkomst met het aanzoek; wij hebben zooeven op, naar ons voorkomt, aannemelijke gronden verworpen, dat óláfr ooit zich in gewichtige zaken zou hebben laten leiden door een oordeel van Hallfreorr. De compilator vindt het noodig Rognvaldr door Hallfreor bij den koning te laten aanbevelen als vrijgevig en betrouwbaar in vriendschap, alsof ' $t$ in Hallfreðr, die in zijn ons bekende onrust van verlangen brandde weer uit Gautland naar Noorwegen, naar den koning, terug te keeren, zou opgekomen zijn tegenover zijn bewonderden vriend den lof van anderen te verhalen.

Het eerste bericht $(a)$ stamt dan uit een Hallfreðar saga, niet uit een mondelìnge, wel uit een schriftelijke saga, want niemand wil den compilator andere dan geschreven bronnen laten gebruiken. Maar welke dan? Er is ons in hs. 132 (Havn. A. M.) een afzonderlijke Hallfreðar saga bewaard gebleven, en in mijn meergenoemde verhandeling heb ik getracht aan te toonen, dat onze compilator een schriftelijke Hallfreðar saga gekend heeft, door mij S2 genoemd, die met den schrijver van 132 dezelfde bron heeft gehad, welke bron ik $\mathrm{S}^{1}$ noemde. Maar noch in hs. 132 , noch in $\mathrm{S}^{2}$ staat iets over een bezoek van Hallfreðr bij Rognvaldr. En aannemen, dat de compilator 't bericht zelf heeft verzonnen - hij wist dan uit cap. 219 (X), 281 (R), dat Hallfreorr in Gautland was geweest, dus kon hij dan hier, in cap. 224 en 332 wel vertellen, dat dat bezoek Rognvaldr gegolden had dit wordt ons verboden door de kennis van de werkwijze van den compilator, wiens bijdragen immers alleen uit bindingsstof bestaan. Wij worden gedwongen tot het aannemen van een schriftelijke Hallfreðar saga, die verloren is gegaan, en die op bepaalde punten een anderen inhoud had dan de ons bewaarde $\mathrm{S}^{2}$ in de óláfs saga, en de te reconstrueeren $\mathrm{S} 1$, een saga, die door 
haar rijkeren inhoud onzen compilator, die immers op quantiteit verzot is, blijkbaar meer aangetrokken heeft dan de verloren gegane 1 ). Deze verloren gegane saga bevatte in het betreffende stuk niets anders dan dat Hallfreorr naar Haleyrr $\left.{ }^{2}\right)$ ging; vandaar zich naar Konungahella begaf, het grenspunt tusschen Noorwegen (Vík) en Gautland; dan het plan opvatte Rognvaldr te bezoeken; in Gautland twee jaar verbleef en daar met een inheemsche, heidensche vrouw trouwde; even, in den zomer, bij Óláfr Svíakonungr verbleef en dan, door verlangen gedreven, weer naar Noorwegen terugkeerde.

Ik hoop, dat mijn verhandeling over de Hallfreóar saga van eenig belang is voor het saga-onderzoek in het algemeen en dat, vóór alles, het mij geltukt is aannemelijk te maken, dat de saga in haar mondelinge periode even wèl in staat is stof op te nemen, even zoo expansief is, als in de schriftelijke periode. Voor een deel dekken traditie en saga elkaar: de traditie is de nuchtere feitenmassa, zooals die in de oudste redactie van het Landnámabók bewaard is gebleven; de saga bevat méér, bevat niet alleen de feitenmassa, maar is tevens een verlevendiging van de feiten. De traditie is betrouwbaar en er is niet de minste aanleiding voor ons dit te betwijfelen. Integendeel, de aard van de IJslandsche samenleving in de vroege middeleeuwen, de hooge dunk, dien de aristocratie van haar beteekenis had, dwingt

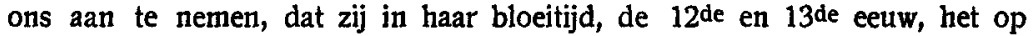
prijs stelde, de daden van haar voorouders in juiste toedracht te bewaren. Tot op zekere hoogte kunnen we het met den handhaver tot het uiterste van de absolute betrouwbaarheị van de familiesaga, Finnur Jónsson, eens zijn, en verdienen wij niet de hevige verwijten ${ }^{3}$ ), die hij ons, buitenlandsche philologen, doet, wanneer wij het wagen maar even te twijfelen. We gelooven aan de betrouwbaarheid, voorzoover het de feitelijkheden betreft, maar we gelooven tevens aan de mogelijkheid, dat elk verteller vrij is geweest om die feitelijkheden naar zijn inzicht te bewerken. Björn Ólsen heeft in een reeks schoone opstellen over de verhouding van de saga's tot het Landnámabók 4) zoo duidelijk aangetoond, dat de oudste redactie van dit werk volkomen betrouwbaar is, terwijl de jọgere redacties, Sturlubók en Hauksbob door sagastof overwoekerd zijn, die de belangrijkheid der sagahelden, bijv. van Egill, wil verhoogen, door welke bewerking in die redacties innerlijke tegenspraak ontstaat, die hij op meesterlijke wijze aan het licht heeft gebracht. Neckel wijst op 't feit ${ }^{5}$ ), dat de bewaarde text van de Njáls saga Gunnarr

1) Ik kwam in genoemde verhandeling, op grond van den toestand der schriftelijke overlevering, tot de conclusie, dat er een schriftelijke Hallfreðar saga moet bestaan hebben met, op bepaalde punten, anderen inhoud dan de ons bewaarde. Ik kom hier langs anderen weg tot dezelfde conclusie.

2) Men vergelijke voor Haleyrr's ligging: Munch, Samlede afhandlinger III (1875) blz. 632 vigg.; Danske Samlinger for Historie og Topographi VI (1870) blz. 289 vlgg., waar men aangaande deze zaak een opstel zal vinden van $O$. Nielsen; en het door N. M. Petersen samengestelde geographisch register op de vertaling van de Fornmannasögur XII (1837) blz. 140. Mijn vriend Jón Helgason te Kopenhagen maakte mij op deze voor ons minder toegankelijke werken opmerkzaam. Voor ons is hier slechts van belang, dat niemand Haleyrr elders zoekt dan om en bij Helsingør.

3) Hinn sidoasti bardagi Gunnlaugs og Hrafns (Skírnir 89)

4) Aarbager 1904 vlgg.

5) Oermanisch-Romanische Monatschrift 1911. 
alléén laat zijn bij den nachtelijken overval, terwijl een der latere Landnámatexten hem nog door één dienaar laat vergezeld zijn. De waarheid was, dat er verscheidene geweest zijn, dat de achtereenvolgende vertellers telkens één lieten vallen, tot er geen meer overbleef, en dat de genoemde Landnámatext de saga op een vroeger punt van ontwikkeling heeft opgevangen dan onze schriftelijke fixeering. Dat de saga een mondelinge periode heeft gehad, verschillende philologen hebben in hun verschillende werken telkens en telkens weer de voorhanden zijnde bewijsplaatsen aangehaald; ik acht me van den plicht ontslagen die bewijzen hier opnieuw aan te voeren 1 ). Ik stel me die mondelinge saga aldus voor: de verteller verhaalde van een reeks daden van zijn held; zijn relaas was geheel en al in den en toen en toen vorm gegoten; de vorm, dien we in de schriftelijke fixeering bijv. van de Hallfreðar, de Vatnsdœla, de Eyrbyggja saga bewaard hebben, en dien we natuurlijk ook in de overlevering van de Egils, Njáls en Gunnlaugs saga herkennen kunnen, maar dáár kan, dunkt me, minder van schriftelijke fixeering dan van litteraire bewerking sprake zijn. Voor den saga-man was er bij dien en toen - en toen vorm, gelegenheid te over anecdoten op te nemen, op plaatsen, waar de traditie dun was, zijn stof te vergrooten, om aldus zijn held te verheerlijken. Zoo kon en moest de saga in het gradueele onbetrouwbaar worden. Wat willen dan toch de handhavers van de absolute betrouwbaarheid? Volgens hen is de traditie - die zij zich dan toch wel volkomen vormloos moeten voorstellen - heel lang betrouwbaar geweest en dan ineens, bijv. nà 1275, wordt ze onbetrouwbaar! Deze philologen scheiden te sterk traditie en saga; de traditie, de kern, blijft, volgens onze meening, tot in lengte van dagen betrouwbaar, maar de saga niet. In de $12^{\text {de }}$ eeuw, wanneer de sagavertelling begint, begint ook de traditie onder de saga bedolven te worden, begint dus de onbetrouwbaarheid, en op 't eind der 13 de eeuw eindigt de sagavertelling tegelijk met haar beoefenaars, de IJslandsche aristokratie; dan kan er alleen nog maar van schriftelijke ontwikkeling sprake zijn.

Om tot ons uitgangspunt terug te keeren: de Hallfreðarsaga was arm aan traditie: de veete met Gríss om Kolfinna, de zwerftochten en het huwelijk in Gautland, de genegenherd voor koning óláfr zijn de hoofdpunten. Veel was er niet; ja, in de bewaarde schriftelijke fixeering zijn nog verschillende punten, waar het blijkt, dat de sagaverteller de traditie onaangetast heeft gelaten, waar niets te vertellen valt. 't Was op zoo'n punt, dat de verteller op het denkbeeld kwam de traditie aan te vullen en te verlevendigen met wàt dan wel Hallfreor in Gautland overkwam. De betreffende episode haal ik hier aan in haar twee redacties, $S^{2}$, d.w.z. $X$ en $R$, en hs. 132. Men vindt haar in redactie $X$ in cap. 175; in red. $R$ in cap. 280 ; in hs. 132 in cap. 7 . I $k$ acht het niet noodig het geheele verhaal te citeeren; alleen het begin worde hier afgedrukt.

1) In een voordracht op het Amsterdamsche Philologencongres (1919) over het onderzoek van de famliesaga beloofde ik op enkele punten nog eens dieper te zullen ingaan. Ik doe dit door dezen en hoop over 't zelfde onderwerp nog enkele stukken te schrijven. 


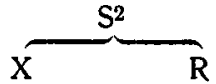

Einn dag um várit, er $H$. var ${ }^{1)}$ fyrir konungi, mælti hann; leyfi vilda ek piggja ${ }^{2}$ ) af yorr, herra, at sigla í sumar kaupfero suðr til Haleyrar. Konungr mælti: eigi skal pat banna pér. Eptir pat bjóz H. ok sigldi til Danmerkr sem hann hafōi ætlat; hann hafoi spurn af Sigvalda jarli, at hann var hofoingi mikill. $H$. kom á fund hans ok sagơiz ${ }^{3}$ ) hafa ort um hann kvæơi. Jarl spurōi, hverr hann væri. $H$. sagõ $i$ nafn sitt ${ }^{4}$ ). Jarl mælti : ertu skáld Óláfs konungs Tryggvasonar? Svá er, segir H., vilda ek nu hljóo fá at flytja kvæðit. Jarl svarar: hví mun oss pat eigi sœmiligt er Óláfr konungr lætr sér vel líka. H. foerơ $i^{5}$ ) kvæðit ok var pat flokkr. Jarl pakkaði honum kvæőit ok gaf honum gullhring pann er $v \hat{a} \mathbf{6}$ ) hálfa mork, ok bauð honum með sér at vera. $H$. svarar : hafið pokk fyrir boðit, herra, en ek á erendi til Svípjóðar ok vero ek pó fyrst at venda aptr til Noregs, pá er ek verð liðugr. Jarl bað hann gera, sem hann vildi. At áliơnu sumri sigldi H. sunnan til Vikrinnar 7 ) ok fekk storm veơrs, brutu skipit austanfjarðar ok tyndu fé ollu; fór $H$. paơan til Konungabellu ok dvaldiz par um hrío. hs. 132

Pat var eitt sinni, er Hallfreor var fyrir konungi, at hann mælti : leyfi vilda ek hafa í sumarat sigla austr til Eyrar kaupferð. Konungr segir: eigi skal pat banna pér. Síoan fór $H$. á brott, hann spurơi, at Sigvaldi jarl var hôfơingi mikill. H. kemr á fund hans ok kvez hafa ort um hann kvæői. Jarl spyrr: hverr ertu? hann segir nafn sitt. Jarl segir: ertu skáld Óláfs konungs? Svá er, segir $H$., ok vilda ek hljóo fá. Jarl segir: hví mun mér pat eigi vel sama, er Óláfi konungi líkar vel. Hallfreör kvað kvæðit ok var pat flokkr. Jarl pàkkaõi honum kvæðit ok gaf honum gullhring, pann er vá hálfa mqrk, ok bauo honum pá at vera meô sér. H. pakkaði honum boð̃; en til Svípjóðar skal nú fyrst fara. Jarl bað hann ráða, pat sama haust fór $H$. i Vík austr ok brutı par skipit austanfjaroar ok týndu fé miklu. paőan fór Hallfreðr til Konungahellu ok dvaldiz par um hrið

\footnotetext{
1) stód (R). 2) hafa (R). 3) kvez (R) 4) til sin (R). 5) flutti (R). b) stó (R).
} 7) at Vikinni (R). 
De oudste saga, de verlorene, meldde het volgende: 10 Hallfreŏr gaat naar Haleyrr, $2^{0}$ vandaar gaat hij naar Konungahella, $3^{0}$ dan begeeft hij zich naar Gautland, naar Rognvaldr. De jongere saga, de bewaarde, vertelt: 10 Hallfreor gaat naar Haleyrr, $2^{0}$ vandaar gaat hij naar Sigvaldi Strútharaldsson, 30 dan begeeft hij zich in de richting van Vík, 40 hij lijdt schipbreuk, 50 hij gaat naar Konungahella, $6^{0}$ hij begeeft zich naar Gautland. Hoe moeten we ons .de verhouding tusschen traditie en saga's in dit geval voorstellen? Op een bepaald punt in Hallfreðr's leven meldde de traditie niets meer, dan dat hij bij een of ander voornaam persoon, ergens in Denemarken of Zweden verblijf hield, daar van dien man een ring ontving als belooning voor zijn skaldengaven, in Gautland met een inheemsche, heidensche vrouw trouwde, met wie hij dan naar Noorwegen terugkeerde, die spoedig stierf en na wier dood hij zich weer mengde in de veeten op IJsland, en bij de satt tusschen hem en Gríss moet hij den ring afstaan als boete. De eerste sagaverteller vulde deze feitenmassa aldus aan: Hallfreðr gaat op een handelsreis naar Haleyrr, vandaar via Konungahella naar Gautland; de voorname persoon is Rognvaldr; van hem krijgt Hallfreor den ring. Te gemakkelijker viel 't den sagaverteller Rognvaldr te kiezen, omdat hij dan ook Hallfreơr in Gautland bracht, waar hij hem in verband met zijn huwelijk noodig had. De tweede sagaverteller varieert aldus op hetzelfde thema: Hallfreor gaat op een handelsreis naar Haleyrr, vandaar naar Sigvaldi Strútharaldsson, dien hij zich terecht voorstelt wonende daar in de buurt, wat zuidelijker, op Sjælland; bij hem is Sigvaldi de voorname persoon, van wien Hallfreorr den ring krijgt. Vandaar gaat hij via Konungahella naar Gautland, waar hij velerlei dingen beleeft. Het vervolg is dan in beide saga's gelijkluidend geweest. De tweede sagaverteller laat Hallfreorr Sigvaldi Strútharaldsson antwoorden: ik moet naar Zweden 1). Tot Sigvaldi kon deze man Hallfreơr niet laten zeggen: ik moet naar RQgnvaldr, omdat in zijn inkleeding Rognvaldr verviel, voor dezen geen plaats meer was, daar Sigvaldi aan Rognvaldr gesubstitueerd werd. Maar deze man had Hallfreðr toch óók in Gautland noodig, in verband met zijn huwelijk; dus liet hij Hallfreor de geciteerde woorden zeggen. Maar hij wil nu gaan vertellen van vreeselijke dingen, die Hallfreor in Zweden (Gautland) overkomen, hoe hij, van alles beroofd, in Konungahella rondloopt, niet weet wat te beginnen, zich aan den Gautlander Auðgísl verhuurt als geleider, met hem 't land intrekt, vele gevaren doorstaat, zich als een vechtersbaas doet kennen; èn zegt de verteller, die vrouw uit Gautland was nu niemand anders dan de weduwe van dien Auðgísl, dien Hallfreðr zoo dapper gewroken heeft. Deze tweede verteller moet dus Hallfreŏr, van alles beroofd, in Konungahella brengen. Hij laat $\mathrm{nu}$, wel wonderlijk, Hallfreðr Sigvaldi nog meer antwoorden, niet alleen, dat hij naar Zweden moest, maar ook dat hij eerst naar Noorwegen wilde gaan 2), toch wel om Hallfreðr zijn in Haleyrr gehaalde koopwaar, dáár, in Noorwegen (Vík), aan den man te laten brengen. Hallfreor begeefi zich dan ook naar Noorwegen, maar de sagaverteller laat

1) Til Svipjoðar skal nú fyrst fara (132), ek á evendi til Svípjóbar (X en R).

2) Wel is waar staan deze woorden niet in hs. 132, maar dit hs. heeft op talrijke plaatseu zijn voorbeeld, dat zeer dicht bij $\mathrm{S}^{2}$ stond, slecht bewerkt, zooals ik in meergemelde verhandeling trachtte aan te toonen. 
zijn tocht niet gelukken; vlak bij Konungahella lijdt hij schipbreuk en verliest alles.

Finnur Jónsson, die twee semesters mijn leermeester was, met wien ik dikwijls over sagaonderzoek mocht spreken, staat vreemd tegenover de vragen, die ons hier bezig houden. Ik herinner mij een gesprek over de verhouding van de Eiriks saga rauõa tot de z.g. Grcenlendinga páttr, een vraagstuk, dat eenige overeenkomst vertoont met dat van de verhouding tusschen onze beide Hallfreðar saga's, en dat ik in een volgend opstel hoop te behandelen. Hij zeide toen: alleen de Eiríks saga rauða is betrouwbaar, en toen ik hem vroeg: maar hoe is dan uw verklaring van de Gronlendinga páttr, die in het feitelijke de Eiríks saga rauơa grootendeels dekt, wat hij dan ook zelf erkent ${ }^{1}$ ), toen antwoordde hij: daar liggen: "mørke traditioner" te gronde. Maar ik kon me door dit antwoord niet voldaan gevoelen, en trachtte een andere oplossing te vinden. Het bevredigt niet aan te nemen, dat een verduistering der traditie nà 1275 zou hebben plaats gehad. Finnur's redeneering mist allen grond en ontduikt de moeilijkheden; want èn de „verduistering" moet óók háár bron gehad hebben, èn het is, zooals ik reeds zeide, niet te bewijzen, dat die verduistering juist dàn zou plaats gegrepen hebben. Onze eerlijkheid komt in 't gedrang: bestaan er twéé overleveringen, dan kan er maar één betrouwbaar zijn : alleen reeds door ' $t$ feit, dat er twéé zijn, valt het absolute betrouwbaarheidsdogma. Er moet naar een andere oplossing gezocht worden. Wanneer men traditie en saga's' uiteenhoudt, en aanneemt, dat traditie, dat wat aan bijv. hier, onze beide Hallfreðar saga's, ten grond ligt, wèl betrouwbaar is, en dat de sagavertellers recht en plicht hadden om naar vermogen en lust te varieeren, reeds dadelijk, zoodra de

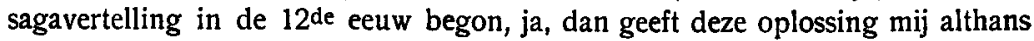
mèèr bevrediging. En niets zal mij aangenamer zijn, dan gedachtewisseling; ik zal deze meeningen in andere opstellen nog nader toelichten.

De bronnen van onze varianten zijn deze geweest: Sigvaldi Strútharaldsson ${ }^{2}$ ) was een door skalden zeer geliefd aristokraat; Hallfreơr in zijn omgeving te brengen was niet in strijd met de rede. De verteller wist, dat hij in dien tijd nog leefde, want hij was tegenwoordig bij, en zeer actief in den slag bij Svoldr. En wat de vreeselijke gebeurtenissen in Gautland betreft: Konungahella en het binnenland werd ongetwijfeld zóó dikwijls door IJslanders bereisd, dat een publiek vertellingen over de roofzucht en woestheid dier heidensche mannen grif aannam. Wat hij hier van Hallfreor vertelde, kon zeker wel één van zijn auditorium overkomen zijn, ja misschien hem zelf.

De epische poëzie, die op IJsland voor een groot deel aan de sagavertelling vóórafging, vertoont dezelfde varianten als de saga's vertoonen kunnen Over Sigurðr en Atli, Guðrún en Brynhildr zijn verschillende gedichten overgeleverd; elk op zich zelf vertegenwoordigt het individueele standpunt van den kunstenaar tegenover zijn stof, een kern van feitelijkheid.

Kan het ook met de saga's niet zoo zijn?

\section{Alkmaar.}

W. VAN EEDEN.

1) Opdagelsen af og rejserne til Vinland (Aarbøger 1915).

2) Pórorr bijvo, de vader van den grooten skáld van Óláfr Haraldsson, Sighvatr, verbleef lang bij Sigvaldi. Men vergelijke de afzonderlijke Óláfs saga $H$ cap. 38; die in de Heimskringla cap. 43. 